\title{
Experimental Investigation of Tribological Characteristics of Blends of SGME Modified with Copper Oxide Nanoadditivation
}

\author{
Eknath Aitavade* and Sannappa Kamate \\ Hirasugar Institute of Technology, Nidasoshi, Belgavi, Karnataka, India \\ ('Corresponding author's e-mail: enaait@yahoo.co.in)
}

Received: 11 October 2020, Revised: 19 June 2021, Accepted: 29 June 2021

\begin{abstract}
Biofuels mixed with petro-diesels have become a sine qua non in environmental protection. They have friction and wear mitigation attributes and so enhance power saving and CI-engine life. The present research focuses on exploration of friction and wear features of Simarouba-glauca methyl-ester (SGME) blends in petro-diesel, with and without nanoadditivation employing 4 ball tribometer as per ASTM D 4172. The experiments were carried on B10 (10\%biodiesel in diesel), B20, B30 and diesel B0. Nanoadditivation of copper oxide $(\mathrm{CuO})$ was done in the amounts of $0.20,0.50,0.75$ and $1 \%$ wt. (weight) with SGME. There was 80 and $49 \%$ reduction in the friction coefficient and minimum wear than that for pure diesel (B0). Wear scars of the balls were characterized by means of scanning electron microscope (SEM). The interfaces exhibited a permutation of abrasion and adhesion mode of wear.
\end{abstract}

Keywords: Friction and wear, Four ball tester, Simarouba glauca, Bio diesel

\section{Introduction}

Biofuels exhibit very good lubricity than traditional counterpart. The biofuel modified by nanoadditivation has further improvements in friction and wear properties. CI-engine parts' life (especially fuel injection system and pumps) is enhanced. Friction and wear properties of CI-engine fuel are of the essence to enhance life of CI-engine components. It helps to increase safety of the interface from damage. It also reduces the power expenditure by lessening friction amongst CI-engine parts [1,2]. Good lubricity is extremely vital for some parts like fuel injectors and pumps because these use fuel itself for lubrication purpose. The lubrication properties of conventional petro-diesel fuel are extremely inferior in comparison with the FAMEs (Fatty Acid Methyl Esters). Consequently, it is exceptionally significant to discover some unusual fuel to handle the increasing requirements [2,3]. Numerous biofuels manifest superior tribological performance as compared to traditional petro-diesels. Some show more wear damage due to rust and interface deterioration. This does non-acceptable damage to CI-engine. This limits its application scope. This emphasizes friction and wear investigation of various biofuels and employment of novel nanoadditives for solution of the above restrictions [3]. In addition, a few ignored biofuels require deployment as such.

Nanoparticles are widely deployed to develop the friction and wear properties of lube-oils. Its utilizations have indicated positive outcomes. Various nanoadditives are experimented comprising Lanthanum Carbonate $\left(\mathrm{La}_{2} \mathrm{CO}_{3}\right)$ [2], different phases of Aluminium Oxide $\left(\mathrm{Al}_{2} \mathrm{O}_{3}\right)$ [4], Cerium Oxide $\left(\mathrm{CeO}_{2}\right)$ and Titanium dioxide $\left(\mathrm{TiO}_{2}\right)$ [5], Copper Oxide $(\mathrm{CuO})$ [6,7], Magnesium doped Zink Oxide (ZMO) [8], Hexagonal Boron Nitride (hBN) [9], Lanthanum Oxide $\left(\mathrm{La}_{2} \mathrm{O}_{3}\right), \mathrm{La}_{2} \mathrm{CO}_{3}$ [10], Multiwall Carbon Nano Tubes (MWNT) [11], Silicon dioxide $\left(\mathrm{SiO}_{2}\right)$ [12], Carbon nanoparticles-amorphous carbon, graphite and graphene [13,14] and Halloysite nanotubes [15] etc. The noteworthy aspects while employing nanoadditives are its appropriate solution and fractional amount on in base oil. The fine dispersal is effected by sonicator.

In the supplementary testing [16] FAME generation out of a variety of kernels was evaluated. It demonstrated that Simarouba-glauca as the future feedstock for methyl ester production. Its crop growing was started by NBPGR, Orissa, India. This unnoticed biodiesel was employed in engines. The following Table 1 shows the comparison of SGME and petro-diesel from the outcomes of various studies. 
Table 1 Comparison of SGME performance with diesel [16-19].

\begin{tabular}{|c|c|c|}
\hline Sr. No. & Parameter & Comparison with petro-diesel \\
\hline 1 & Brake thermal (bTH) efficiency & $\begin{array}{l}\text { Less as compared to petro-diesel } \\
\text { But for B20 to some extent larger }\end{array}$ \\
\hline 2 & $\mathrm{~A} / \mathrm{F}$ ratio & More than diesel \\
\hline 3 & $\mathrm{HC}$ and smoke (B50) & Reduced in the amounts of 22 and $33 \%$ in that order \\
\hline 4 & $\mathrm{HC}$ and smoke (B100) & Reduced in the amounts of 40 and $27 \%$ in that order \\
\hline 5 & NOx & $\begin{array}{c}\text { B100 - } 8 \% \text { rise } \\
\text { B50 - } 5 \% \text { rise } \\
\text { Overall characteristics very alike as petro-diesel }\end{array}$ \\
\hline
\end{tabular}

Consequently, SGME demonstrates to be budding and remarkable alternative to the conservative petro-diesel. The rising oil costs, the diminution of the raw fossil fuels quantity on the earth and the assertion to guard the environment from contaminated desecrate originated from lube-oil and its uncontrolled spillage have developed significance of preparing and employing alternative oils. Bio lubeoils are replacement to conventional lubricants due to its intrinsic attributes as well as eco-friendliness. Vegetal bio lube-oils usually exhibit added lubrication properties, extra viscosity index (VI), high flash point, and lesser vapor form depletion. Vegetal lube-oils are able to be employed in boundary as well as hydrodynamic systems. It is due to their elongated FA chains and the subsistence of polar clusters in the configuration of vegetal lubricants [20].

Consequently, tribo explorations of SGME are indispensable for establishing its appropriateness in wear and friction characteristics. In this research testing and investigation of wear as well as friction characteristics of diesel, blends of SGME with and without nanoadditivation is carried out employing the 4 ball tribometer. The $\mathrm{CuO}$ nanoadditivation was done.

\section{Materials and methods}

\section{Materials}

The FAME utilized in this research was taken out from Simarouba glauca kernels. Transesterification procedure was employed in which elemental breakup of biofuel is effected using alcohol plus esters of alcohol leading to formation of glycerol. The triglyceride is altered by sequential exclusion of an alkyl to a diglyceride, a monoglyceride and lastly a glycerol as secondary creation. The objective is to reduce the thickness of main vegetal lubricant to improve flowability.

\begin{tabular}{|c|c|}
$\begin{array}{c}1 \text { mole x Renewable } \\
\text { fat or oil } \\
(1000 \mathrm{~kg})\end{array}$ & $\begin{array}{c}3 \text { mole x Methyl } \\
\text { esters } \\
(1004.5 \mathrm{~kg})\end{array}$ \\
\hline+ & + \\
\hline $\begin{array}{c}\text { Catalyst } \\
\text { mole x Methanol } \\
(107.5 \mathrm{~kg})\end{array}$ & $\begin{array}{c}1 \text { mole x Glycerol } \\
(103 \mathrm{~kg})\end{array}$ \\
\hline
\end{tabular}

Figure 1 FAME reaction balance [1]. 
Table 1 The important physicochemical attributes of biodiesel.

\begin{tabular}{|c|c|c|c|}
\hline Sr. No. & $\begin{array}{c}\text { Attribute } \\
\text { (Relevant standard) }\end{array}$ & Assessment & Instruments used (Model) \\
\hline 1. & Flash point: [ASTM:D93] & $138^{\circ} \mathrm{C}$ & $\begin{array}{l}\text { Pensky Marten Flash Point Apparatus } \\
\text { (RICO-Closed Cup) }\end{array}$ \\
\hline 2. & $\begin{array}{c}\text { HCV } \\
\text { [ASTM D6751,IS 1350-1966, IP12/63 T] }\end{array}$ & $37.5 \mathrm{MJ} / \mathrm{Kg}$ & $\begin{array}{c}\text { Semiautomatic Digital Bomb Calorimeter } \\
\text { (Hamco 6b) }\end{array}$ \\
\hline 3. & Kinematic Viscosity: [ASTM:D445] & $\begin{array}{c}5.38 \mathrm{~mm}^{2} / \mathrm{s} \text { at } \\
40^{\circ} \mathrm{C}\end{array}$ & $\begin{array}{l}\text { Kinematic Viscosity Bath } \\
\text { (HAMCO, 48H2-STD6) }\end{array}$ \\
\hline 4. & Density: [ASTM:D1448] & $0.876 \mathrm{gm} / \mathrm{cc}$ & $\begin{array}{c}\text { Hydrometer } \\
\text { (Leimco, M-50SP) }\end{array}$ \\
\hline
\end{tabular}

\section{The key physicochemical properties of blends}

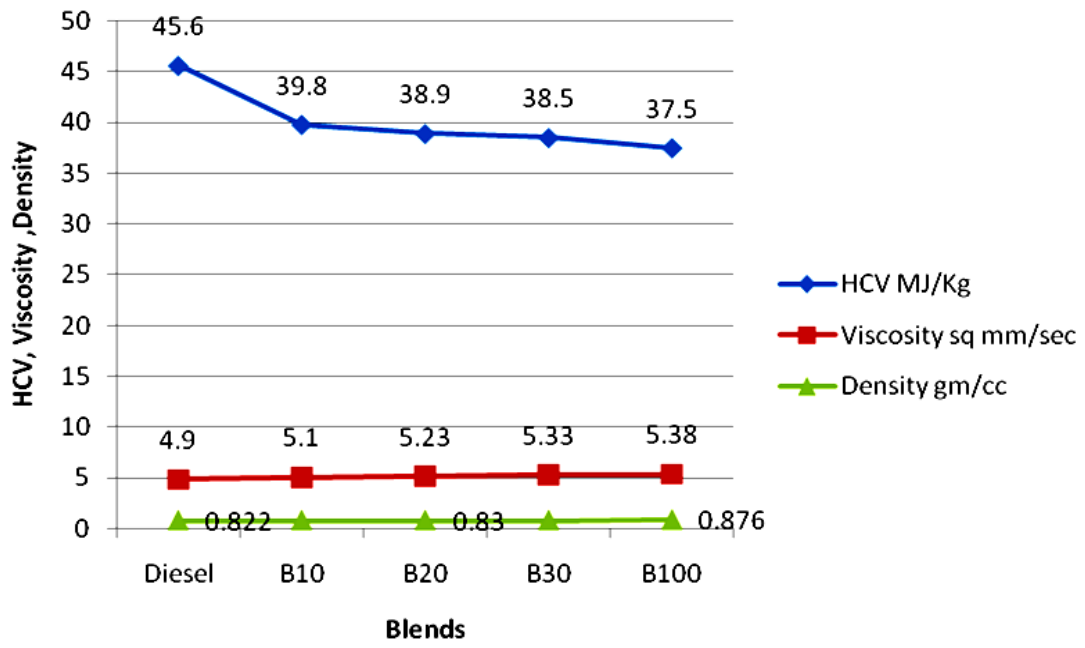

Figure 2 The vital physicochemical attributes of blends.

The remainders are gums, waxes and triglycerides. Although ethanol is favored for the making of FAME because of environmental friendliness and non-pernicious nature, methanol is generally in use as it is comparatively cheap. FAMEs are on the top popularity. Figure $\mathbf{1}$ depicts chemical balance. The vital thermo-physical characteristics of SGME mixtures are revealed in Table $\mathbf{1}$ and Figure $\mathbf{2}$ in that order. The $\mathrm{CuO}$ nanoparticles were used. The $\mathrm{CuO}$ nanoparticles were chosen due to their better-quality performance in the contrast with alternatives as well as outstanding properties. Bulk nano $\mathrm{CuO}$ can retain its spherical profile even after diffusion because of higher density and melting point [21]. Also, it is environmental friendly and self-sustaining. Thus, it is proposed to inspect the scope of applications of $\mathrm{CuO}$ nanoadditives by employing it for present investigation. The analysis report of the $\mathrm{CuO}$ nanoparticles shows: Almost globular shape, Normal Elemental Dimension of 20 (nm), Standard mass $6.31 \mathrm{~g} / \mathrm{cm}^{3}$ and Purity $99.5 \%$.

\section{Methods}

Making of nanoadditivated SGME

The $\mathrm{CuO}$ nanoadditives were separately mixed in the main SGME in fractions of $0.2,0.25,0.75$ and $1 \%$ wt. by means of LABMAN sonicator LMUC-3. Sonication is done for $15 \mathrm{~min}$ duration. Every nanoadditivated sample was ensured for its stability lasting a week's duration. 


\section{Making of various blends of SGME}

Table 2 depicts particulars of the neat biodiesel specimens. Volume basis mixtures of neat and additivated SGME were arranged with 10,20 and $30 \%$ proportion. Likewise, for nanoadditivated biodiesel taken as a whole 16 specimens were arranged as revealed in Table 3. Proportional amount condition nanoadditivated specimens were made. The ingredients were parent biodiesel with nanoadditives having $0.2,0.5,0.75$ and $1 \%$ amounts. The investigation was done on the specimens depicted in Table 3.

\section{Tribological tests}

The wear and friction experiments were conducted in 4 ball tribometer. The arrangement of the experimental mechanism is indicated in Figure 3. The entire equipment was made dirt free prior to every experiment. The neat $\mathrm{B} 0$ and other 15 specimens were tested in the oil container of the equipment. ASTM D4172 experimental conditions were stringently followed. Chrome alloy steel AISI standard E52100 steel experimental spheres were employed with size of $12.7 \mathrm{~mm}$, Grade 25 EP (Extra Polish) and a hardness of 64 - 66 HRC. Experimental outcomes were analyzed thoroughly. All the parts were made dirt free using acetone following each experiment. Wearing amount was estimated as the mean WSD of the 3 bottom balls. The COF was logged in as concurrent instant in each of the experiment. The experimental parameters for every specimen were as below:

1) Test Load is $392 \pm 2 \mathrm{~N}$.

2) Test duration is $3,600 \mathrm{~s}$.

3) Speed is $1,200+/-60 \mathrm{rpm}$.

4) Temperature is $75^{\circ} \mathrm{C}+/-2^{\circ} \mathrm{C}$.

Worn out ball's exterior faces were examined by means of SEM for selected balls manifesting the maximum and minimum wear scar diameters.

Table 2 Blends of petrodiesel and neat biodiesel.

\begin{tabular}{ccc}
\hline Sr. No. & Blend Details & Amount of specimen \\
\hline 1. & Pure Diesel: (B0) & \\
2. & Petrodiesel with $10 \%$ neat biodiesel: (B10) & $50 \mathrm{~mL}$ \\
3. & Petrodiesel with $20 \%$ neat biodiesel: (B20) & \\
4. & Petrodiesel with $30 \%$ neat biodiesel: (B30) & \\
\hline
\end{tabular}

Table 3 Specimen particulars with proportional amount of nanoadditives, petrodiesel and biodiesel.

$\begin{array}{lll}\text { Sr. No. Particulars } & \text { No. of Specimen }\end{array}$

1. $\quad$ Neat petrodiesel: (B0) 01

2. Petrodiesel + Neat biodiesel: $($ B10, B20 and B30) 03

3. Petrodiesel + Nanoadditivated biodiesel with $\mathrm{CuO}:(0.2,0.5$,
0.75 and $1 \%$ wt. $)$ and $\mathrm{B} 10, \mathrm{~B} 20$ and $\mathrm{B} 30$ variation. 


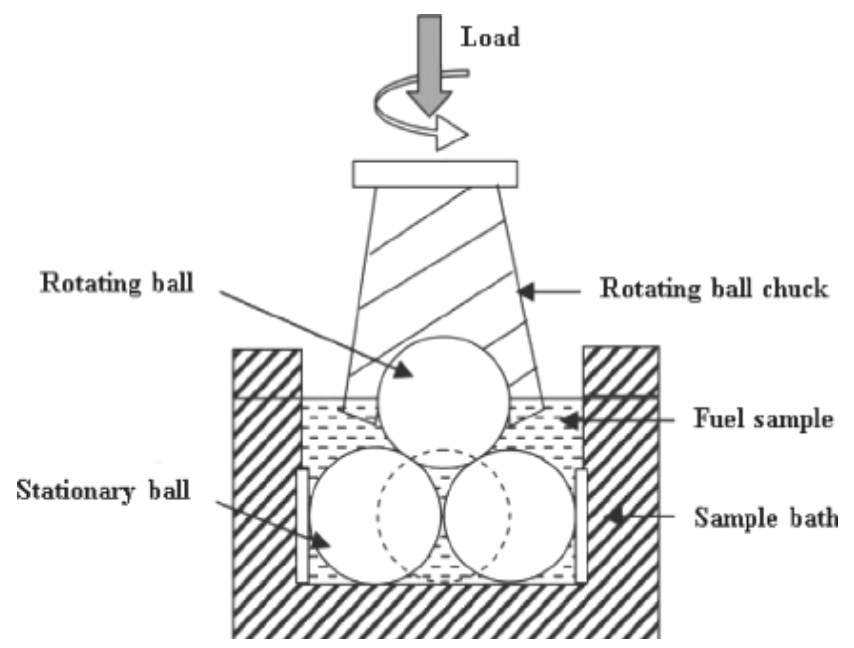

Figure 3 Four ball tribotester arrangement [Adaption from 3].

\section{Results and discussion}

\section{Friction analysis}

After experimentation on different 16 combinations of diesel, SGME and nanoparticles depicted in Tables 2 and $\mathbf{3}$ the following outcomes were manifested.

Figures 4 and $\mathbf{5}$ show influence of percentage of biodiesel on COF and average COF respectively. The COF progressively reduces when amount of SGME changes from 10, 20, to $30 \%$. The $30 \%$ of Simarouba shows the minimum average COF due to higher viscosity than other variants i.e., $79 \%$ lower than that for B0. The decrease in friction parameter in the existence of $\mathrm{CuO}$ nanoadditives is credited to ball bearing behavior nanoadditives. The miniature furrows are generated and then further globular nanoadditives enter the interface region similar to petite spherical bearing, decreasing the coefficient of friction. Furthermore, nanoadditive mending effect on the worn surface was seen, leading to reduction of $\mathrm{COF}$ at interface. Conversely extra amount of nanoparticles lead to inferior lubricating behavior.

Figures 6 to 9 show the effect of the different percentage combination of diesel, SGME and $\mathrm{CuO}$ Nanoparticles with wt. \% of $0.2,0.5,0.75$, and $1 \%$ on COF respectively. Figures 10 to 12 show the effect of different percentage combination of diesel, SGME and CuO Nanoparticles with wt. \% of 0.2 , $0.5,0.75$, and $1 \%$ on average COF respectively. From Figures $\mathbf{6}$ to $\mathbf{1 2}$ the best result (lowest average $\mathrm{COF}$ ) is observed for $30 \% \mathrm{SGME}$ (B30) and $0.2 \mathrm{wt} \% \mathrm{CuO}$ nanoadditives which is $80 \%$ lesser in contrast with neat diesel (B0). It is the combined outcome of less agglomeration and patch-up consequence of nanoadditives with B10 biodiesel variant owing comparatively elevated viscosity.

\section{Wear analysis}

Figure 13 shows that for pure SGME (without nanoadditivation) the WSD gradually decreases as the blend \% increases to $30 \%$. It is $42 \%$ lower than that for B0. The variation of WSD with respect to different combinations of SGME and nanoparticles as shown in Figures 14 - 16 indicates that the lower percentage of SGME leads to improvement in the results. Also, these charts show that if additive concentration is increased the WSD of blended oil also varies. B0 manifested adhesion type wearing as depicted by Figure 17. On the other hand, the entire wear exposed by additivated biodiesel was abrasion type. Wearing mode is credited to the coating of nanoadditives at the worn interface, hence enhancing the wear characteristics. The nanoadditive coating at mating interface creates protecting layer with little hardness as well as Young's modulus [22]. This may also be attributed to some tribochemical reactions happening at the interface [23].

In case of modified SGME blends, wearing mode is credited to the mending of yielding $\mathrm{CuO}$ nanoadditives at the interface, consequently enhancing the wear attributes. This reduces COF and wearing in that order due to increase in the resilient warpage at interface. This coating primarily takes place due to the tiny dimension of nanoadditives as well as its effective dispersion in the biodiesel. In the course of relative motion at contact surface, nanoadditives effortlessly enter at the interface that prevents straight contact of the surfaces. Furthermore, the coating of nanoadditives on the wearing surfaces reduces the 
tangential stress, and therefore lessens COF and wearing. SEM micrograph in Figure 19 depicts a lot of finer worn finish, representing that the nanoadditives were mended on the wear interface.

The wear of steel ball in $\mathrm{B} 10$ blend and $1 \%$ amount of $\mathrm{CuO}$ of nanoadditives was observed as the lowest and $49 \%$ lower than that for $\mathrm{B} 0$. This shows that the $1 \%$ wt. $\mathrm{CuO}$ nanoparticles have more dispersiveness in the base oil and also have good load carrying ability.

\section{Worn scar micrographic analysis}

Worn out faces of the balls were characterized using SEM. Figures 17 - 19 depict the SEM images of worn out faces of balls for different bio diesel blends. The micrographs show material fiber fracture. Minimum WSD is observed for B10 blend having $1 \%$ wt. of $\mathrm{CuO}$ nanoparticles. SEM micrograph in Figure 19 indicated a highly fine wear interface, showing that the nanoadditives were mended on the interface. Figure 17 shows grain boundary crack initiation and propagation. This type of fracture takes place due to creep phenomena in which grains are stronger and grain boundaries are weaker. In such cases crack initiation is delayed but once initiated it propagates faster. This may be due to local temperature rise. This is the case of inter granular crack initiation and promulgation due to grain boundary work hardening. It must be because of restricted temperature rise of grain border in addition to drop in ductility [24]. Figures 17 and 18 show localized grain wear and plucking of the grains due to creep phenomena.

Figure 19 for $\mathrm{CuO}$ nanoadditives indicate unvarying dispersed wearing all over in contrast with Figures 17 and 18. Such consistent wear is advantageous for long life of components. Some tiny indentations on the large surface region point to the good finish. This is due to directional wear of surface with burnishing action and some tribochemical reactions at the interface. Also, it shows to a little level 3 body wear of material. Also, nanoparticles' mending on interface enhances its tribological attributes. This also is attributed to the good dispersion of nanoparticles in SGME because of the presence of oleic acid in it $[25,26]$.

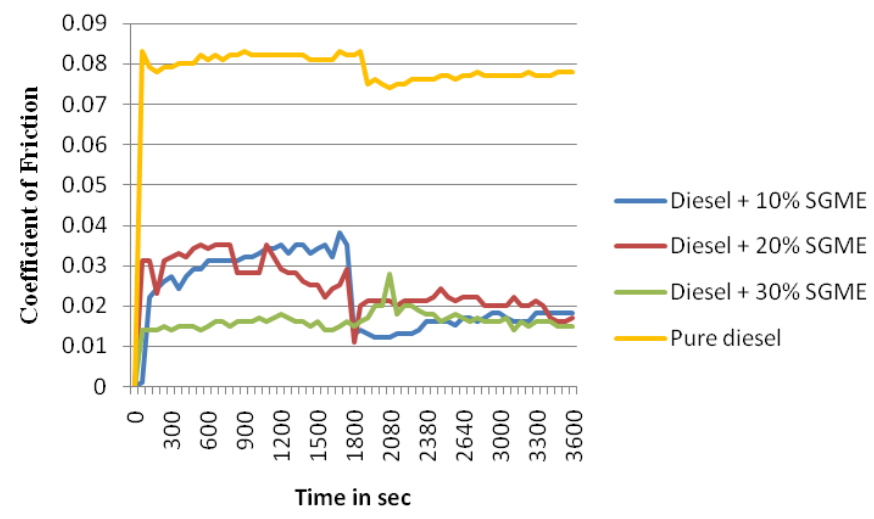

Figure 4 Influence of percentage of biodiesel on coefficient of friction.

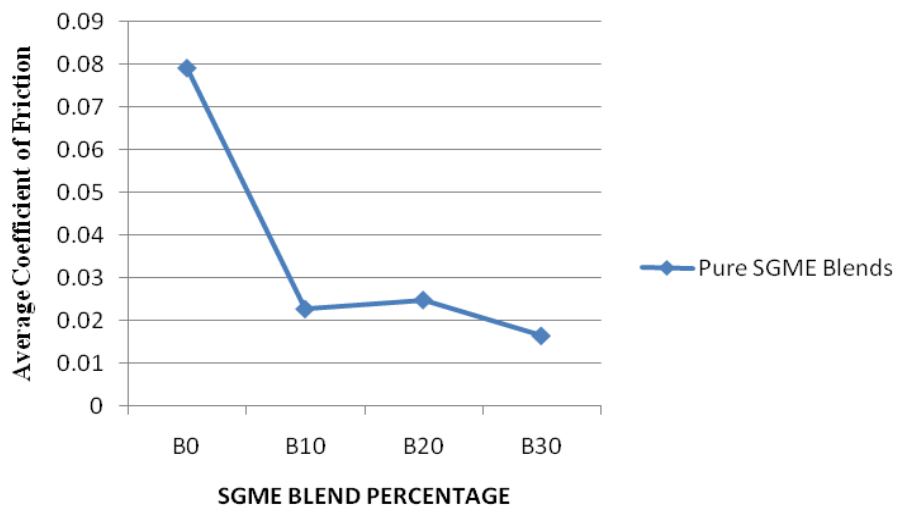

Figure 5 Influence of \% of biodiesel on average coefficient of friction. 


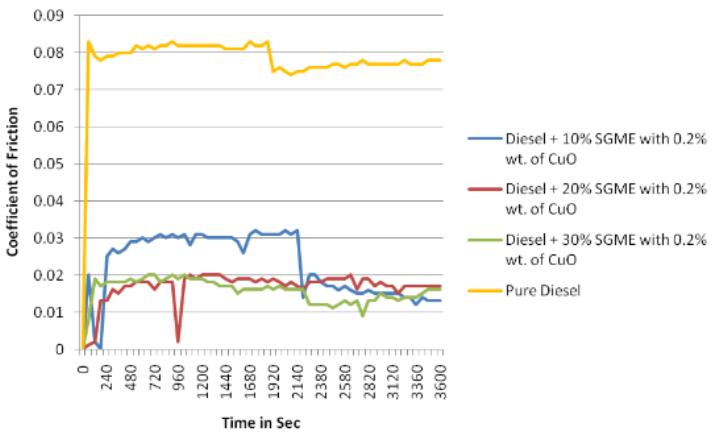

Figure 6 Influence of $0.2 \%$ of $\mathrm{CuO}$ nanoadditives and percentage of biodiesel on coefficient of friction.

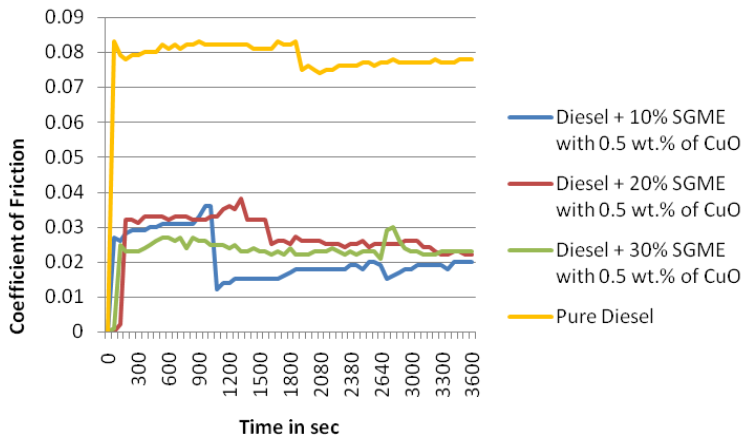

Figure 7 Influence of $0.5 \%$ of $\mathrm{CuO}$ nanoadditives and percentage of biodiesel on coefficient of friction.

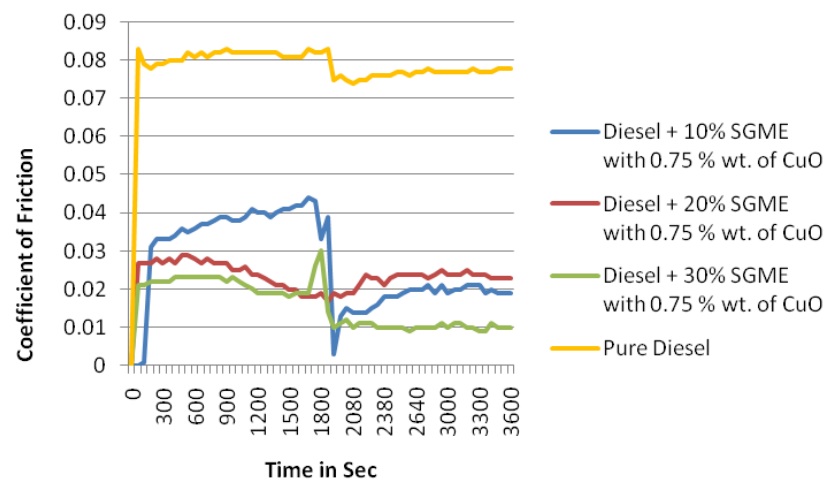

Figure 8 Influence of $0.75 \%$ of $\mathrm{CuO}$ nanoadditives and percentage of biodiesel on coefficient of friction.

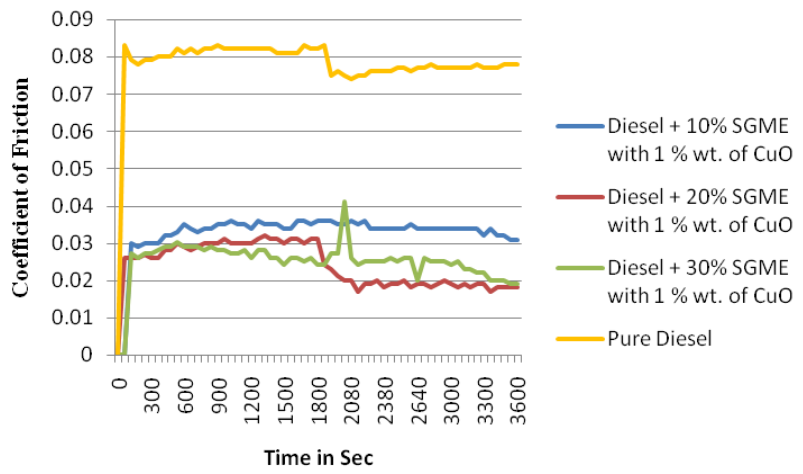

Figure 9 Influence of $1 \%$ of $\mathrm{CuO}$ nanoadditives and percentage of biodiesel on coefficient of friction. 


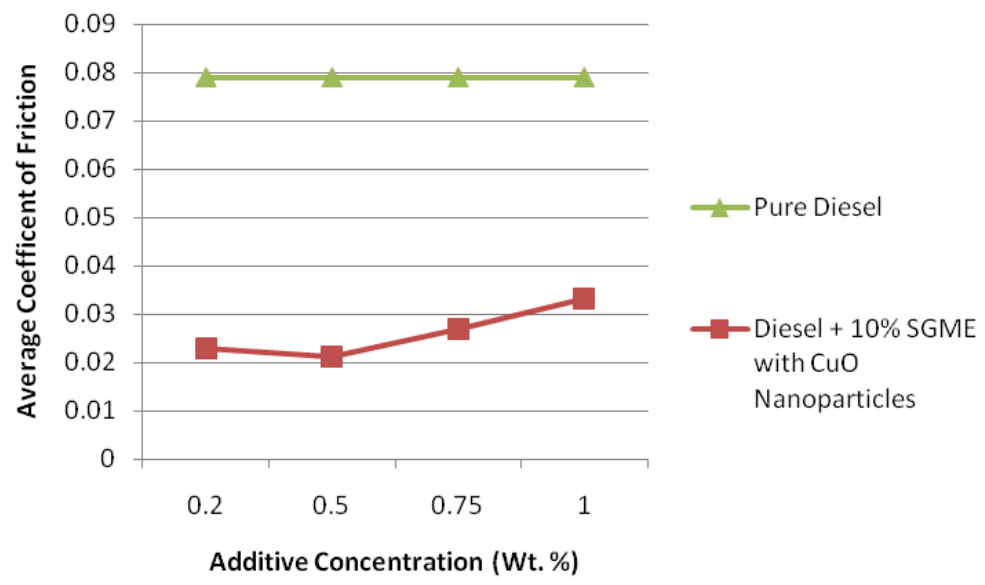

Figure 10 Influence of percentage of $\mathrm{CuO}$ nanoadditives in biodiesel for $\mathrm{B} 10$ blends on average COF.

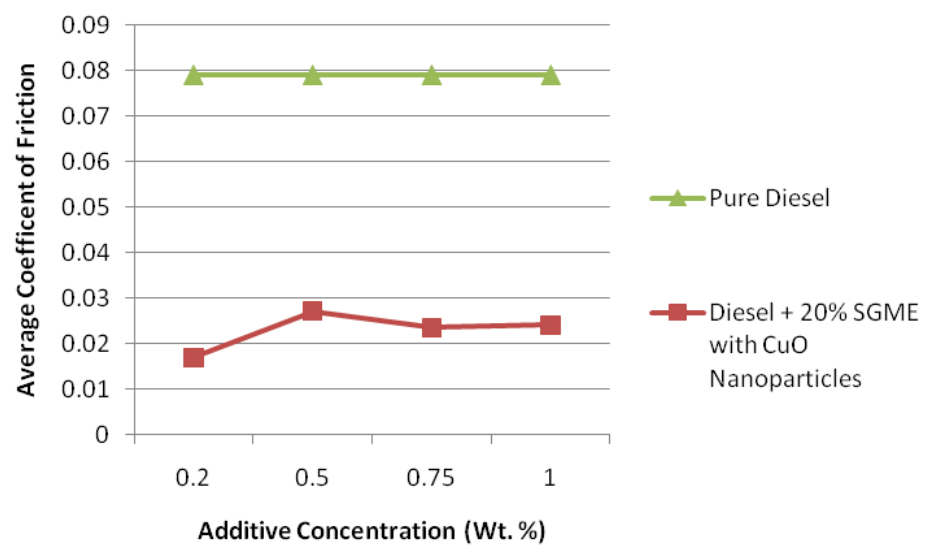

Figure 11 Influence of percentage of $\mathrm{CuO}$ nanoadditives in biodiesel for B20 blends on average COF.

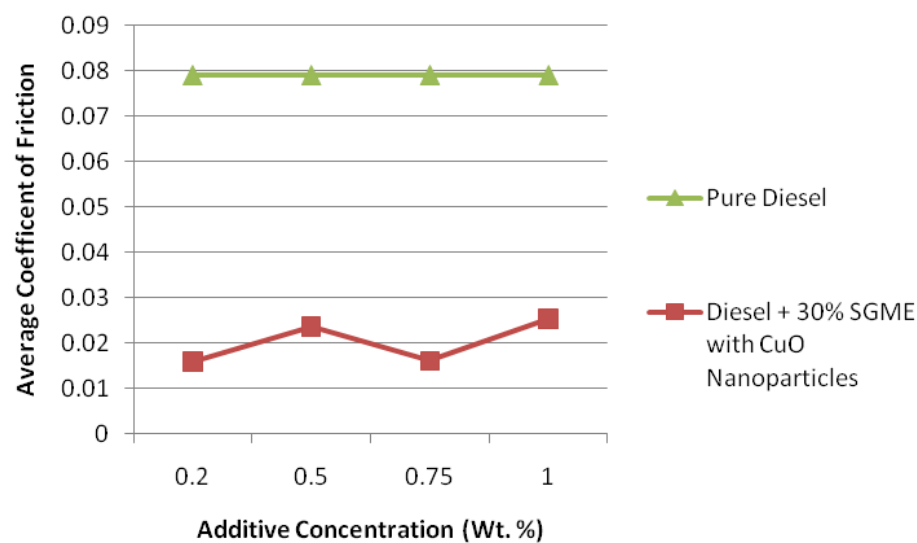

Figure 12 Influence of percentage of $\mathrm{CuO}$ nanoadditives in biodiesel for $\mathrm{B} 30$ blends on average COF. 


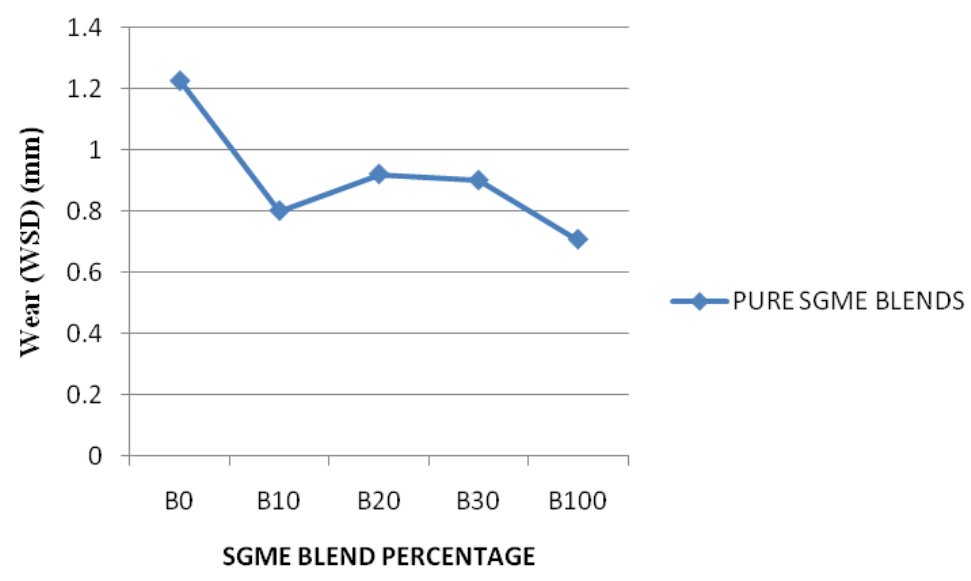

Figure 13 Influence of percentage of neat biodiesel on WSD.

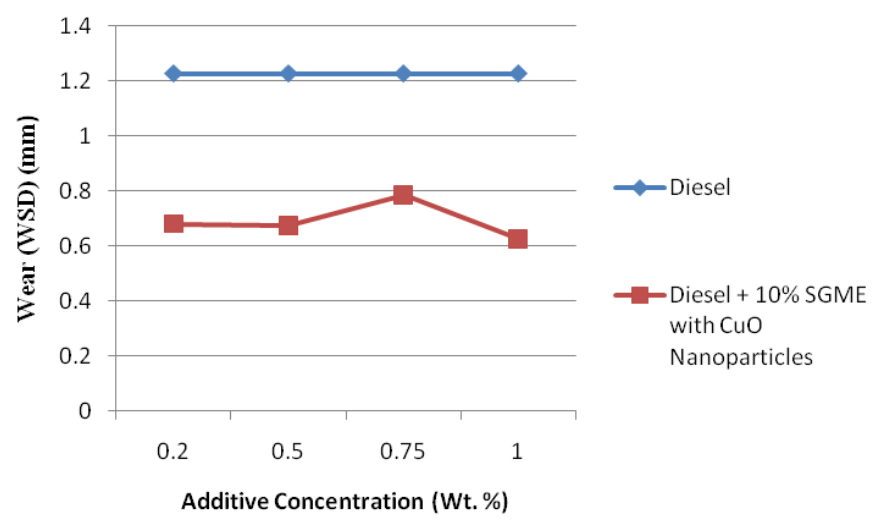

Figure 14 Influence of percentage of $\mathrm{CuO}$ nanoadditives for $\mathrm{B} 10$ blends on WSD.

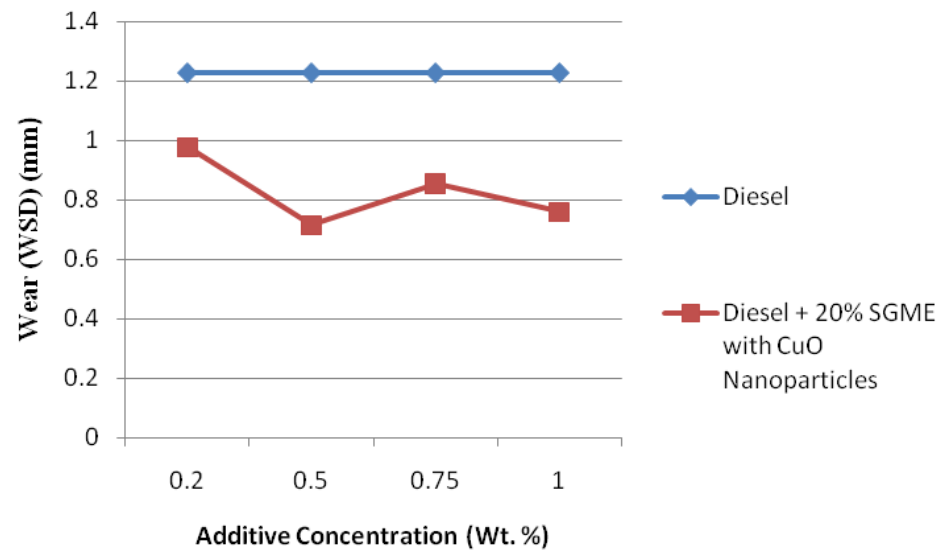

Figure 15 Influence of percentage of $\mathrm{CuO}$ nanoadditives for $\mathrm{B} 20$ blends on WSD. 


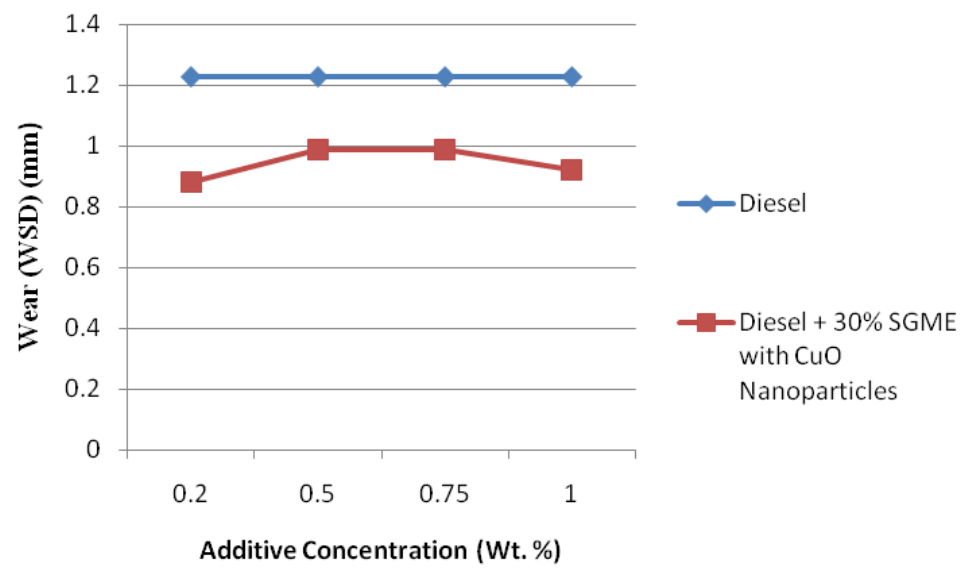

Figure 16 Effect of \% of $\mathrm{CuO}$ nanoadditives for $\mathrm{B} 30$ blends on WSD.

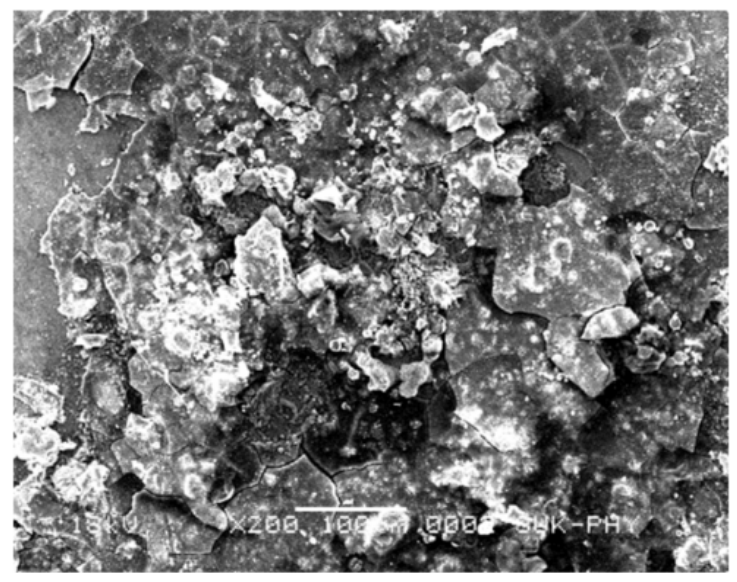

Figure 17 SEM micrograph of worn surface of B0 without blend and nanoadditives (highest WSD-1.226 $\mathrm{mm})$.

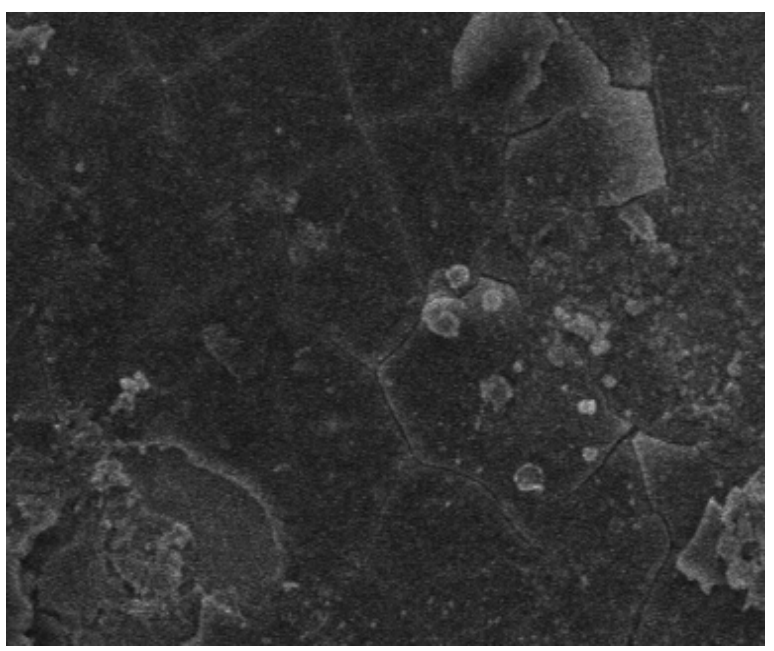

Figure 18 SEM micrograph of worn surface of diesel blend with $30 \%$ SGME and 0.75 wt. \% CuO nanoadditives (maximum WSD-0.987 mm). 


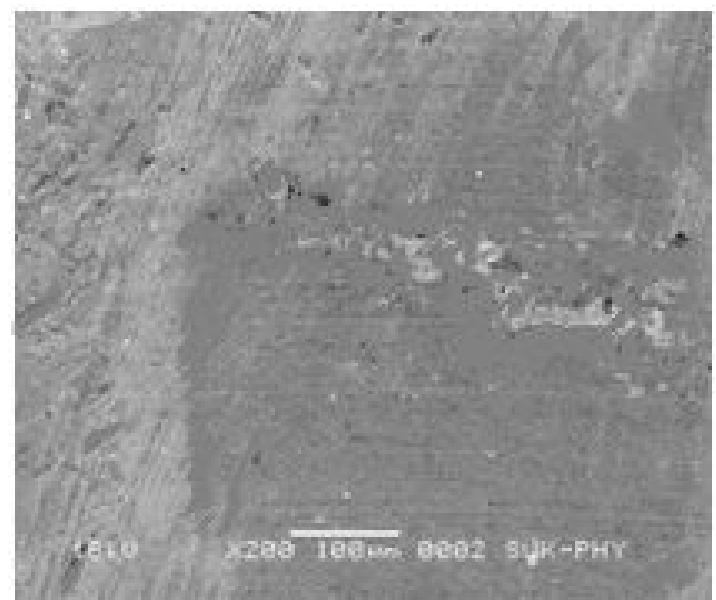

Figure 19 SEM micrograph of worn surface of diesel blend with $10 \%$ SGME and $1 \%$ wt. of $\mathrm{CuO}$ nanoparticles (minimum WSD-0.622 mm).

\section{Conclusions}

The lubricating ability of $\mathrm{CuO}$ nanoparticles as an additive in the SGME depends upon its percentage amounts. Friction diminution, high load sustaining ability and antiwear properties can be achieved using nanoparticles. The investigation of scar surface by SEM indicates the nanoparticles laying down on wear surfaces (mending) i.e., an enhancement of the interface tribological characteristics. Blending of $\mathrm{CuO}$ nanoparticles based SGME in diesel shows that the COF of solution drops with high proportion of blend. This is because of the modification of SGME with nanoparticles and increase in viscosity due to it. Chief mechanism of friction reduction by nanoadditives is credited to rolling consequence, defensive film, 3 body and patch-up properties. Least average COF was observed to be 0.0158 for B30 blend of SGME Oil in diesel and Containing $0.2 \% \mathrm{CuO}$ nanoparticles in it. This is attributed to the promotion of the rolling effect by $0.2 \%$ of $\mathrm{CuO}$ nanoparticles at the point of contact. Minimum WSD of $0.622 \mathrm{~mm}$ is obtained for B10 blend having $1 \%$ wt. of $\mathrm{CuO}$ nanoparticles, which shows that it has good dispersiveness and load carrying capacity. The average friction coefficient (COF) for diesel was 0.0790 obtained during the test. Nanoparticles are easily dispersed in SGME because oleic acid is present in it. Oleic acid imparts good dispersiveness and stability to nanoparticles in SGME by forming an effective chemisorbed modification layer on the surface of nanoparticles. SGME modified with $\mathrm{CuO}$ nanoadditives manifest enhanced friction and wear characteristics than neat SGME. The investigation of worn surface by SEM indicates the nanoadditive deposition on contact interface leading to enhancement of the tribological properties. 


\section{References}

[1] Ng Jo-Han, NH Kiat and G Suyin. Advances in biodiesel fuel for application in compression ignition engines. Clean Technol. Environ. Policy 2010; 12, 459-93.

[2] Y Xu and Y Peng, X Zheng, KD Dearn, H Xu and X Hu. Synthesis and tribological studies of nanoparticle additives for pyrolysis bio-oil formulated as a diesel fuel. Energy 2015; 83, 80-8.

[3] MA Fazal, ASMA Haseeb and HH Masjuki. Investigation of friction and wear characteristics of palm biodiesel. Energ. Convers. Manage. 2013; 67, 251-6.

[4] M Vasheghani, E Marzbanrad, C Zamani, M Aminy, B Raissi, T Ebadzadeh and H BarzegarBafrooei. Effect of $\mathrm{Al}_{2} \mathrm{O}_{3}$ phases on the enhancement of thermal conductivity and viscosity of nanofluids in engine oil. Heat Mass Transf. 2011; 47, 1401-5.

[5] CX Gu, GJ Zhu, L Li, XY Tian and GY Zhu. Tribological effects of oxide based nanoparticles in lubricating oils. J. Marine Sci. Appl. 2009; 8, 71-6.

[6] E Ettefaghi, H Ahmadi, A Rashidi, SS Mohtasebi and M Alaei. Experimental evaluation of engine oil properties containing copper oxide nanoparticles as a nano additive. Int. J. Ind. Chem. 2013; 4, 28.

[7] VS Jatti and TP Singh. Copper oxide nano-particles as friction-reduction and anti-wear additives in lubricating oil. J. Mech. Sci. Technol. 2015; 29, 793-8.

[8] Kalyani, V Jaiswal, RB Rastogi and D Kumar. The investigation of different particle size magnesium-doped zinc oxide $\left(\mathrm{Zn}_{0.92} \mathrm{Mg}_{0.08} \mathrm{O}\right)$ nanoparticles on the lubrication behaviour of paraffin oil. Appl. Nanosci. 2017; 7, 275-81.

[9] N Talib, R Nasir and EA Rahim. Tribology characteristic of hBN particle as an additive in modified jatropha oil as a sustainable metalworking fluid. In: Proceedings of the Malaysian International Tribology Conference, Penang, Malaysia. 2015, p. 199-200.

[10] W Qiongjie, X Yufu, H Xianguo and Z Xifeng. Experimental study on friction and wear characteristics of bio-oil. Trans. Chin. Soc. Agric. Eng. 2008; 24, 188-92.

[11] S Bhaumik, S Prabhu and KJ Singh. Analysis of tribological behaviour of carbon nanotube based industrial mineral gear oil. Adv. Tribol. 2014; 2014, 341365.

[12] AC Mande, SN Mandlik and SR Nimbalkar. Experimental analysis of tribological properties of lubricating oil using nanoparticle additives. Int. J. Adv. Res. Innov. Ideas Educ. 2016; 2, 637-45.

[13] GC Cristea, A Radulescu, C Georgescu, I Radulescu and L Deleanu. Influence of additive concentration in soybean oil on rheological and tribological behavior. In: Proceedings of the International Conference of Aerospace Sciences, Bucharest, Romania. 2018, p. 35-43.

[14] GC Cristea, C Georgescu, D Dima and L Deleanu. Influence of graphene as additive in soybean oil. IOP Conf. Ser. Mater. Sci. Eng. 2018; 444, 022012.

[15] B Suresha, G Hemanth, A Rakesh and KM Adarsh. Tribological behaviour of pongamia oil as lubricant with and without halloysite nanotubes using four-ball tester. Am. Inst. Phys. Conf. Proc. 2019; 2128, 030011.

[16] VB Borugadda and VV Goud. Biodiesel production from renewable feedstocks: Status and opportunities. Renew. Sust. Energ. Rev. 2012; 16, 4763-84.

[17] PK Devan and NV Mahalakshmi. Utilization of unattended methyl ester of paradise oil as fuel in diesel engine. Fuel 2009; 88, 1828-33.

[18] AA Jungman. 2012, Examining the use of simarouba glauca seed oil as a feedstock for the production of biodiesel using a small scale model developed in India. Master Thesis. Florida International University, Florida, USA.

[19] V Kasturi and MC Navindgi. An experimental analysis of performance, combustion and emission characteristics of simarouba biodiesel and its blends on CI engine. Int. J. Mod. Eng. Res. 2014; 4, 79-86.

[20] HM Mobarak, EN Mohamad, HH Masjuki, MA Kalam, KAHA Mahmud, M Habibullah and AM Ashraful. The prospects of biolubricants as alternatives in automotive applications. Renew. Sust. Energ. Rev. 2014; 33, 34-43.

[21] S Baskar, G Sriram and S Arumugam. Experimental analysis on tribological behavior of nano based bio-lubricants using four ball tribometer. Tribol. Ind. 2015; 37, 449-54.

[22] M Asrul, NWM Zulkifli, HH Masjuki and MA Kalam. Tribological properties and lubricant mechanism of nanoparticle in engine oil. Procedia Eng. 2013; 68, 320-5.

[23] NN Gosvami, J Ma and RW Carpick. An in situ method for simultaneous friction measurements and imaging of interfacial tribochemical film growth in lubricated contacts. Tribol. Lett. 2018; 66, 154.

[24] GE Dieter. Mechanical metallurgy. McGraw-Hill Book Company, London, 2017. 
[25] IABS Alves, HM Miranda, LAL Soares and KP Randau. Simaroubaceae family: Botany, chemical composition and biological activities. Braz. J. Pharmacogn. 2014; 24, 481-501.

[26] MS Patil and DK Gaikwad. A critical review on medicinally important oil yielding plant laxmitaru (Simarouba glauca DC.). J. Pharm. Sci. Res. 2011; 3, 1195-213. 